\title{
Social Media for Smart Farmer-Shared Farming Equipment Model
}

\author{
Wuttipong Pongsuwan, Hongladda Pongsuwan \\ Shinawatra University, Pathum Thani, Thailand \\ wuttipong.p@siu.ac.th, hongladda@me.com,wpongsuwan@gmail.com
}

\begin{abstract}
This research offers a roadmap for creating a concept for building a collaborative and connected mobility model to share the agricultural machine. The study aims to adopt those models to create a collaborative and connected mobility model as a Shared Agricultural Machine Network for Smart Farmer. The fact that Thai farmers are facing the aging crisis, like all other industries and farming machinery has become a need for manpower replacement to keep their earning for livings. Unfortunately, these machines are often expensive, so they can own only a few, and when it comes to reaping the harvest season, and they often require different tools for specific purposes. Our survey has shown that farmers have different ways of cultivating different crops at the same time this implies that in harvesting season there are unused agricultural pieces of equipment available to share among them. The model of shared farm equipment could lead to new farmers' way of life and it's time to become smart-farmers. This paper will discuss important considerations, including the need for challenges, trends, and opportunities for farmers to have machinery when needed and to share what idle with others via a peer-to-peer network using mobile application platform.
\end{abstract}

Keywords: Social media networking, agricultural equipment sharing, farming equipment sharing, collaborative mobility, peer-to-peer network

\section{Introduction}

Thailand relies heavily on agricultural sector as the economic growth recorded by the country in the 1970s and the early 1980s was owed mainly to the steady expansion of the agricultural sector (Country Profile Thailand, n.d.). Thailand 4.0 is a sector-specific industrial policy that aims to attract new investment towards transforming the economy. Now and then, Thailand has been passed through three major stages of development as the era of agriculture (Thailand 1.0), a light industrial (Thailand 2.0), and today, a heavy industry (Thailand 3.0). Recently, Thai Government policy vision, Thailand 4.0,-transforming the traditional economy into an innovation-driven economy- agriculture must change from traditional agriculture to modern agriculture (it24hrs, 2017). Typically, farmers who are not aware of seizing this opportunity are just looking for the agricultural machinery and equipment, such as a compact tractor, harvester, cutters, and crane, to increase agricultural productivity. Unfortunately, farming machines are expensive and often a shortage.

When it comes to seeding or harvesting season, especially for the areas that grow similar crops investing new machinery and equipment is one possibility but not a feasible solution for small farm owner. Our survey has shown that farmers have different ways of cultivating different crops at the same time this implies that in harvesting season there are unused agricultural pieces of equipment available to share among them. This article discusses a collaborative mobility model that links farmers and owners of agricultural tools and demonstrates the use of the model by developing a mobile application that is designed to meet the needs of the agricultural tool sharing. The important considerations, including the need for challenges, trends, and opportunities for farmers to have machinery when needed and to share what idle with others via a peer-topeer network using a mobile application platform. A model of shared farm equipment in this research demonstrates that the use of mobile technology has been recognized and can be extended to the potential uses in the future.

\section{Literature Review}

Thailand has an area of about 321 million rai or about 513,000 square kilometers. The area for agriculture is about 43\% (138 million hectares), and agriculture accounts for 10\% of GDP (OECD, 2013). As for agriculture, meeting the challenge of greater productivity and income and employment security requires further efforts to modernize and to educate farmers in the use of technology (OECD, 2013). During this time, mobile technology 
is in place, the digital inclusion policy is aggressively implemented in Thailand which could guarantee that Thai farmer digital accessible. To focus on management and technology used by farmers to make more profit or Smart Farming meanwhile the farmer is an entrepreneur (Bukht \& Heeks, 2018).

The Agricultural Value Chains: In the agricultural value chain, when farmers select crops that are suitable for the season, improve the yield and produce the desired quality, they must invest in agricultural production by purchasing inputs such as seeds, plants, fertilizers and phytosanitary products. Agricultural tools are important inputs in the value chain of agriculture especially in the era when agricultural labor is lacking, while demand for agricultural products continues to grow. However, for the agricultural sector, investing in machine tools wisely would reduce production costs and result in higher incomes for farmers. Figure 1 shows the use of agricultural tools in the agricultural value chain (Agricultural value chains, 2018).

Figure 1: The Uses of Agricultural Tools in the Agricultural Value Chain (A Typical Agricultural Value Chain, 2018)

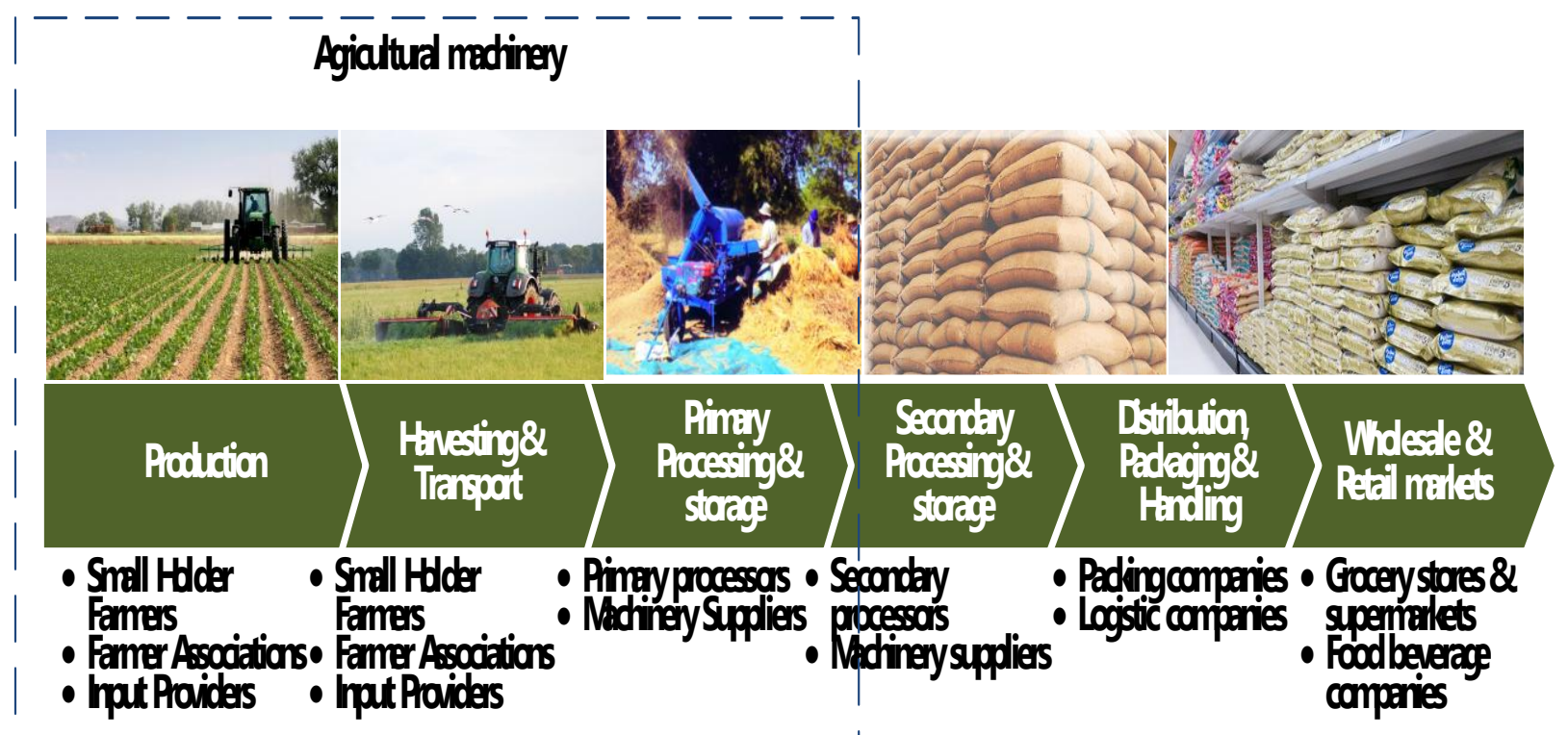

Newer farmers are turning to machines to increase agricultural productivity in a meantime advanced technology has changed the way of life, business, and the world economy. Technology leads to changes in people the lifestyle and business approach. Business sectors initiate new products and services to raises the total value between manufacturers and consumers.

Thai Government Support Policy: Thailand's government in 2016 introduced "Thailand 4.0", an economic model designed to break Thailand out of the middle-income trap. For agriculture, Thailand 4.0 aims at a seven-fold increase in average annual income of farmers from 56,450 baht to 390,000 baht by 2037. Thai farms are small-43 percent of them are smaller than 10 rai, and another 25 percent are between 10-20 rai. These small plots are already mechanized-90 percent use machinery. Concomitantly, agricultural research budgets have dropped from 0.9 percent of agricultural GDP in 1994 to only 0.2 percent in 2017. Meanwhile, the population ages the World Bank estimates that by 2040, 42 percent of Thais will be over 65 years old (Agriculture in Thailand, n.d.). 
Figure 2: Thailand GDP From Agriculture (Trading Economics, n.d.)

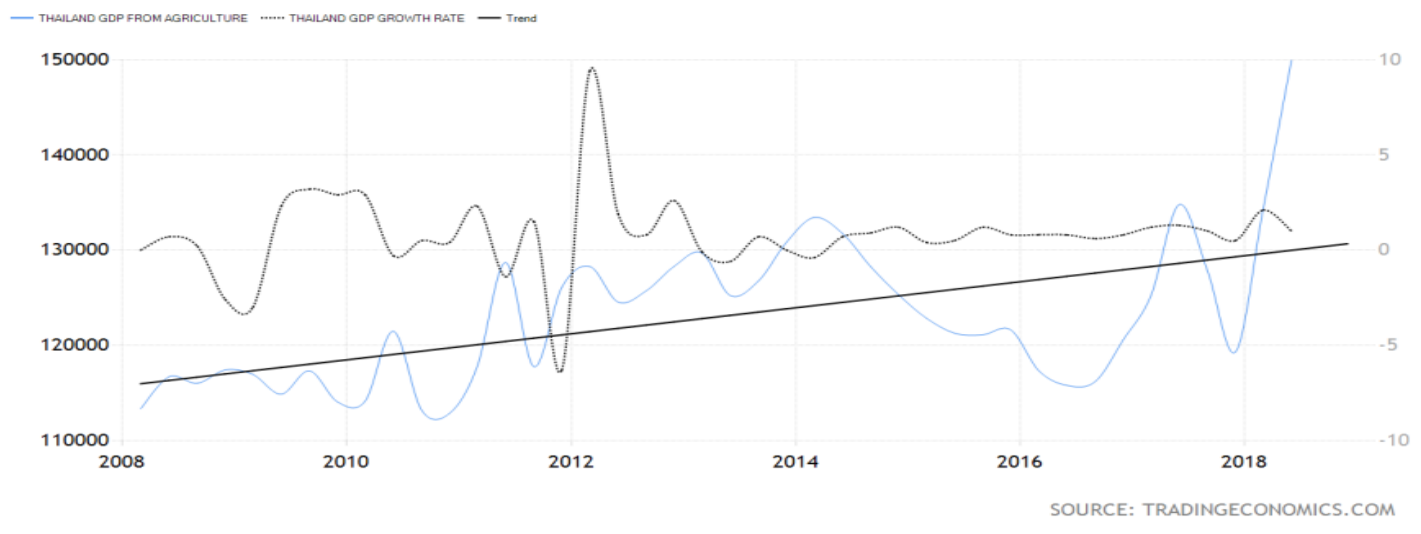

The Trend of Mobile Technology in Thailand: E-Services and mobile commerce have been adopted by various industries and government services. The usage of smart phone is widely used in Thailand (more than 120 Million numbers). However, the internet usages of smartphone are games and social media applications.

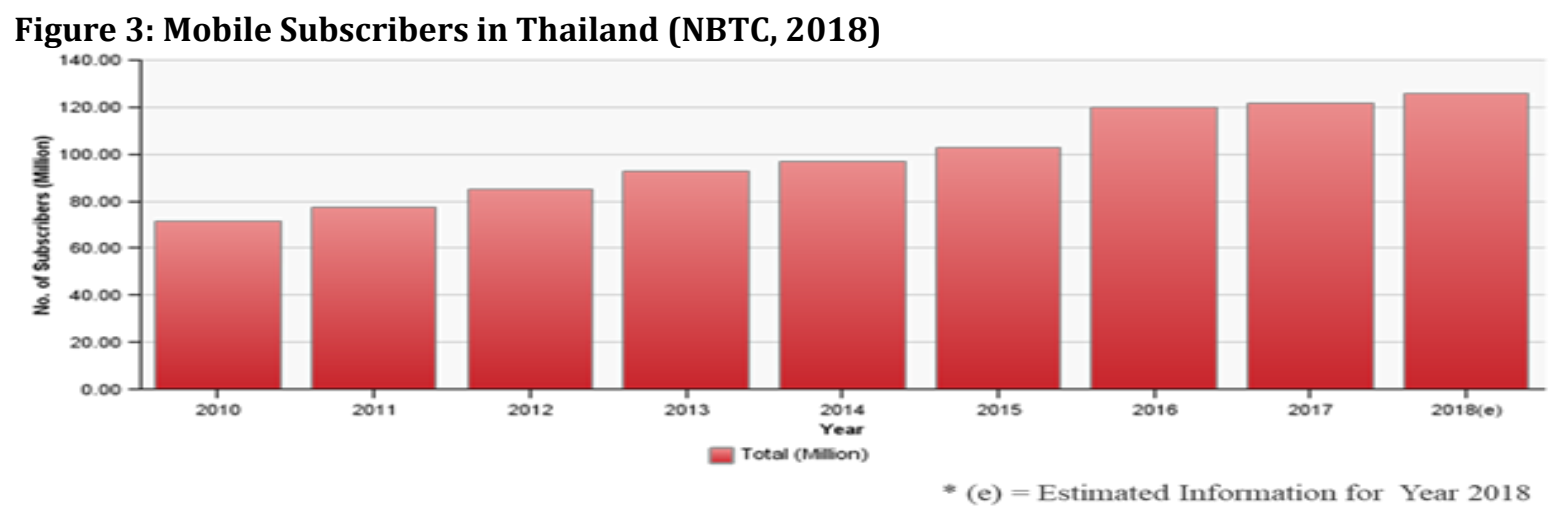

Figure 4: Number of Mobile Subscribers Classified by Service Provider (it24hrs, 2018)

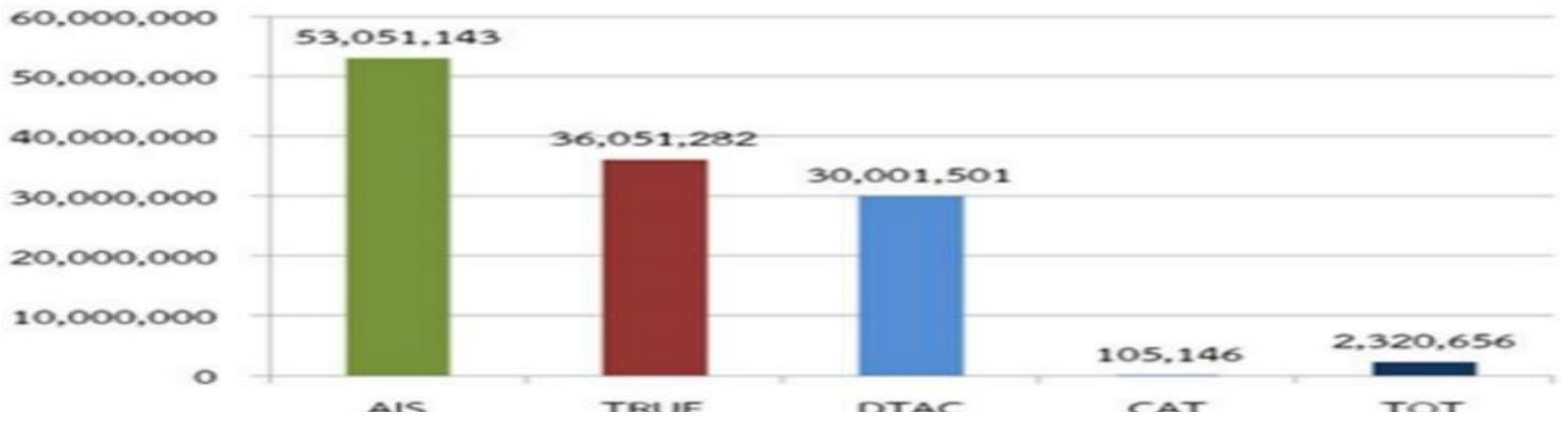

The social media and e-Commerce models are more and more popular in Thailand Number of Facebook and line users are rapidly increased. There's no need for training how to use Facebooks and Lines. The implementation of mobile application based on social media and web will impact farmers and create more impact to the economy. The statistic declares by Thailand Office of National Broadcasting and Telecommunications Commission (2018) show that mobile subscribers in Thailand have been increase from 60 million up to more than 120 million within nine years. For voice data of 3 major operators, between 2557 and 2560, there will be a continuous decline. By the year 2014, the volume of voice services is $70,720.42$ million minutes in 2015, down to 62,851.09 million minutes, in the year 2019 down to 51,021.48 million minutes and in 2560 , there were $43,460.84$ million voice services. In the year 2017 , Thai people use their 
voice over cellular service for an average of 2 minutes per person per day, down from the previous year's average of 4 minutes per person per year provider (it24hrs, 2018) .

Social Media and Social Networking: There are many researches and developments to show the implementation of using social media in conglomerated organization like PTT PCL (Chatchalearmpol, Pongsuwan, \& Vachalobol, 2016). The smart labor that using social media to solve their worker pickup problem (Khongmanee, Pongsuwan, \& Thanawastien) show the relationship with GPS and mobile application to solve smart labor and their transportation to work, Social Communication for Smart Farmers in Durian Society in 2016 show the relationship and combined lifestyles of durian farmers with their customers via social media. (Doungvichitkul, Pongsuwan, \& Thanawastien, 2016). However, the shared equipment like UBER (https://www.uber.com/) or GRAB for shared farmer equipment is not existed in Thailand. Social media and social networking has become a new marketing tool for business where anyone can share opinions and attitudes for their services and any related information. Currently, social media has changed and updated over time in the various contexts of technology development, which influenced human behavior in these days whether communication via the internet or search engine to seek any useful information in daily life, including e-commerce and entertainment activities.

Farm Sharing Model: Sharing farm machinery is implemented in many countries. For example: Basarik and Yildirim (2015) (Doungvichitkul, Pongsuwan, \& Thanawastien, 2016) showed interesting model in Turkey. These are State Machine Park Neighbor assistance, Farm machinery contractor, Machinery partnership, Machinery cooperatives and Machinery rings. Their research found that in Turkey shared farming equipment help in farmers and cooperative to justify demands and supplies but it's still many idle machine and human in the supplied-chain and still has difficulty to control time and places to improve efficient of these farming equipment's.

\section{Research Methodology}

In addressing this issue, comparing to the vast emerging mobile technology platform that applies to passenger vehicles leverages positive indirect network effects between the supply side and the demand sides - like Uber, Grab, etc. - many perceived this as one of the disruptive technologies. Provides a vision of creating holistic and individual farmer through technology, along with examples in the form of adaptive usage an overview of the ecosystem technology to support such a vision is described. This includes monitoring systems, maintenance platforms, and data-driven models to measure the prevalence of the farmer. Finally, this research offers a roadmap for creating a concept for building a collaborative and connected mobility model to share agricultural equipment. This study aims to adopt those models to create a collaborative and connected mobility model called 'Shared Agricultural Machine for Smart Farmer' (SAM-SF). This article will discuss important considerations, including the need for challenges, trends, and opportunities for farmers to have machinery when needed and to share what idle with others via our technology. This research using constructive research model aimed to design, construct, and demonstrate on a mobile application name TFarm on play store and app store. Within the app, farmers together with equipment owners can connect and create a relationship with farmers to farmers, farmers to equipment owners and equipment owners to equipment owners, these relationships create new kind of social media that bring more efficient social power to the shared farming equipment.

The Design and Implementation of T-Farm Application: We developed an application on smart phone and host this app on google Play store and apple Appstore using the name T-Farm. T-Farm has ability to share tractors and other farming equipment such as harvester and cutting glass equipment. By next year, we decide to implement B2B marketplace for matching all truck and labor to provide more efficient farms and smart farmers. The model name Shared Agricultural Machine for Smart Farmer Model was created as shown in figure 5 and figure 6. 
Figure 5: Shared Agricultural Machine for Smart Farmer Model

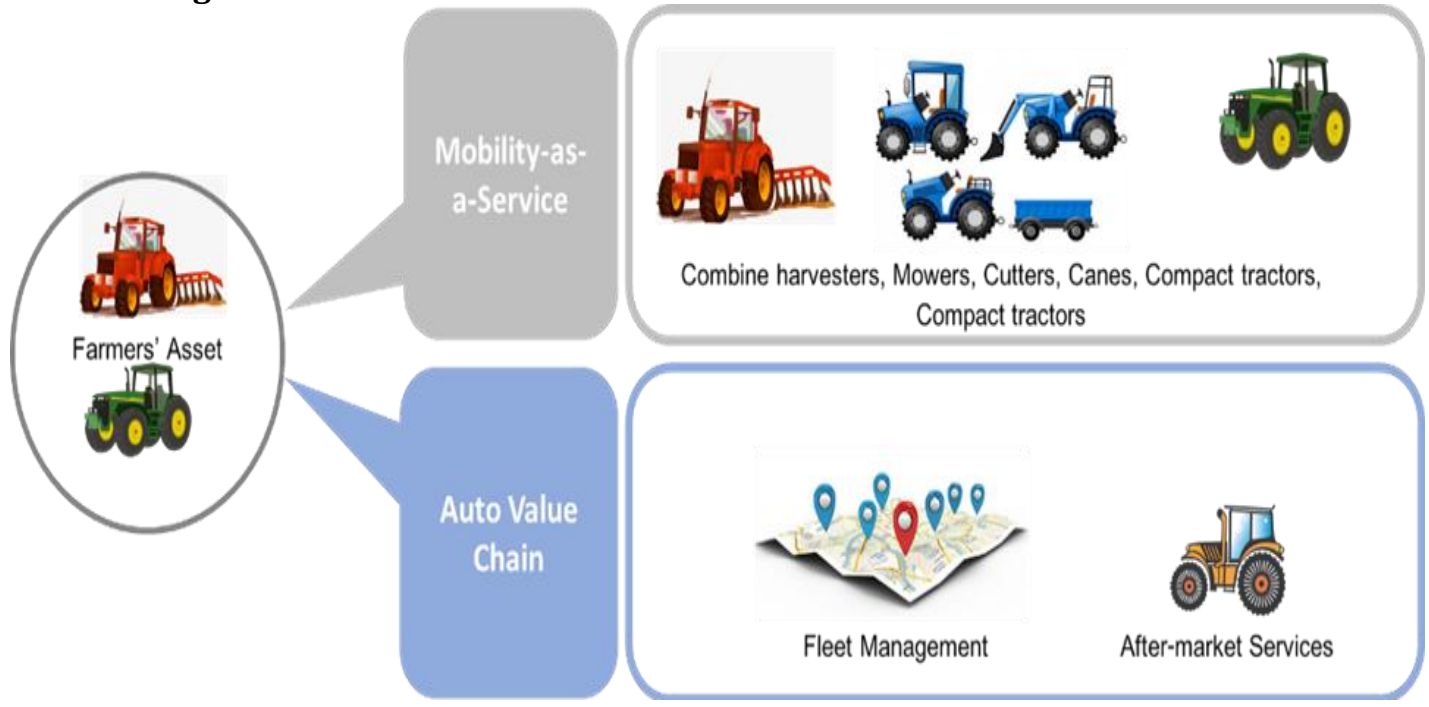

Figure 6: T-Farm Application Conceptual Design

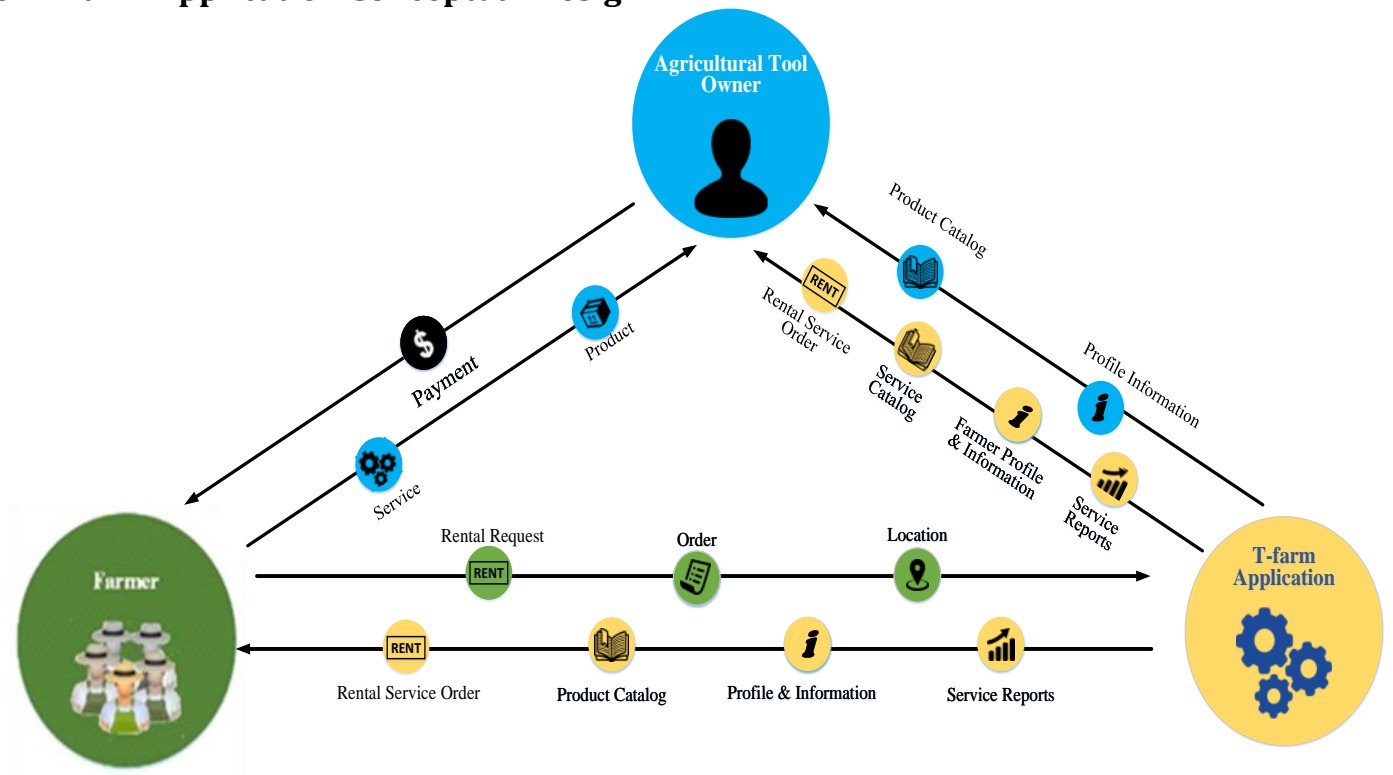

Business Process Modeling: We used android studio to build application on google android phone (JAVA) and swift X-Code for IOS. The design of the program based on web and MS-SQL and C\# on server. Farmers just choose what kind of machine he wants and point and click on location and time that are needed to deploy service on location. This model will provide accurate and precision time to service (no more waiting time for farmers and equipment). Figure 6 showed BPM notation of T-Farm development. Figure 8, 9 and 10 showed the actual implementation and real work of the application. 
Figure 7: T-Farm Workflow Using BPM Notation (Business Process Model and Notation, n.d.)

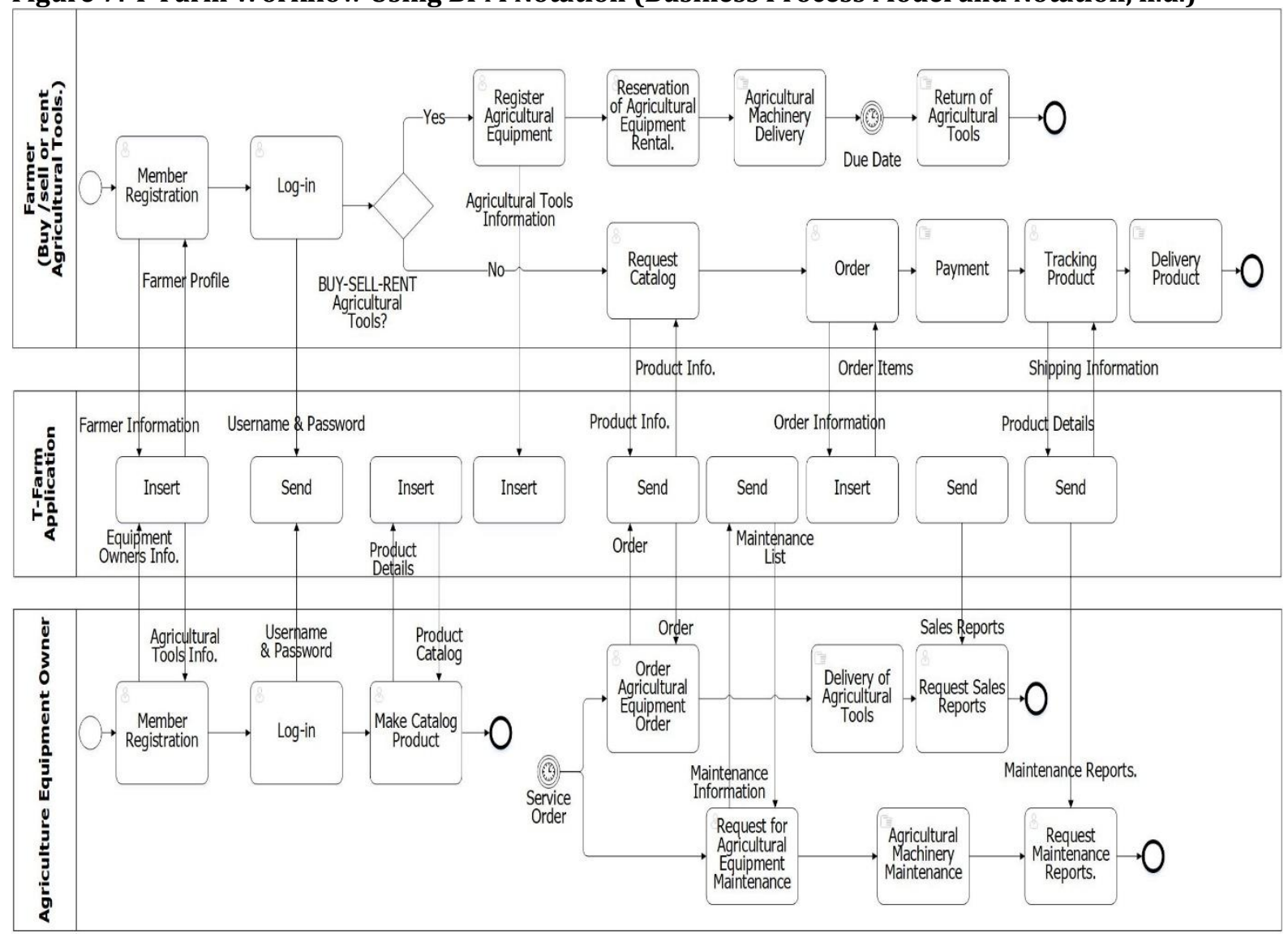

Figure 8: T-Farm Mobile Application

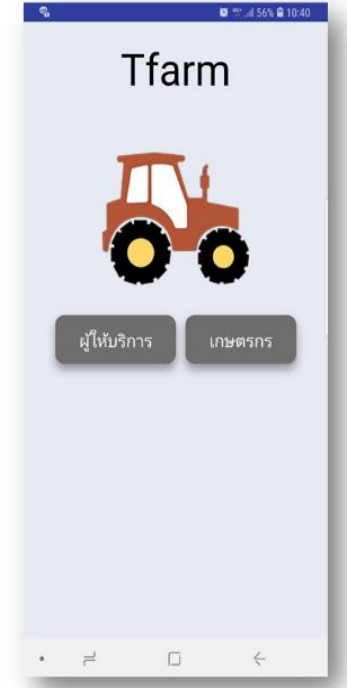

Switching MODE: between Tractor owner / Farmer

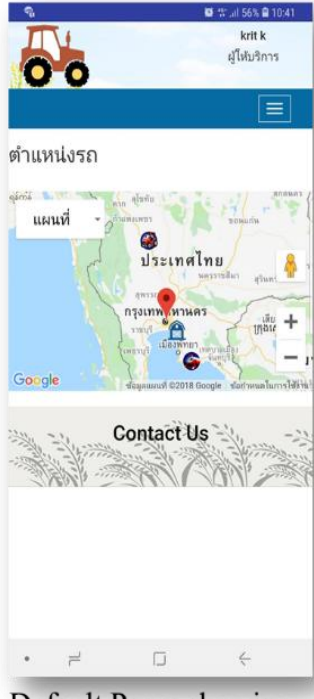

Default Page: showing current Machine Location

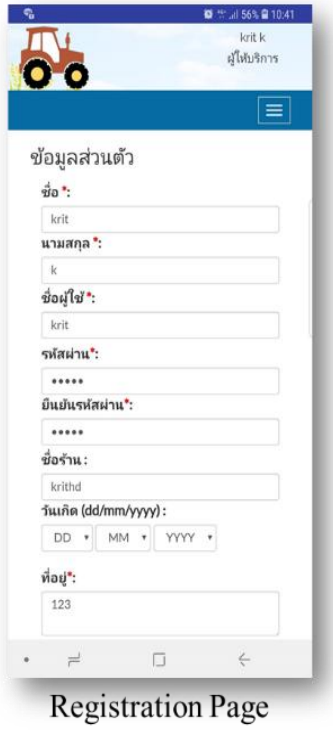

Registration Page 
Figure 9: T-Farm Application Service both Farmers and Equipment Providers via Location Based (GPS) on Smartphone
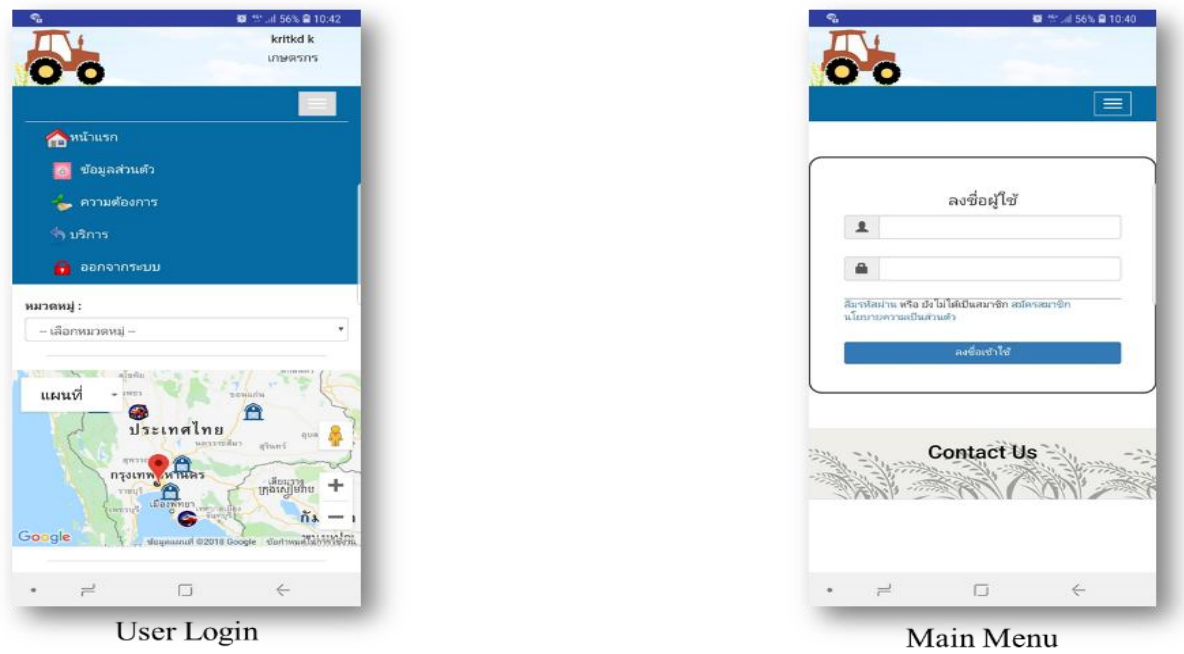

Figure 10: T-Farm Application Show Input Form to Match between the Demand and the Availability of Farming Machine
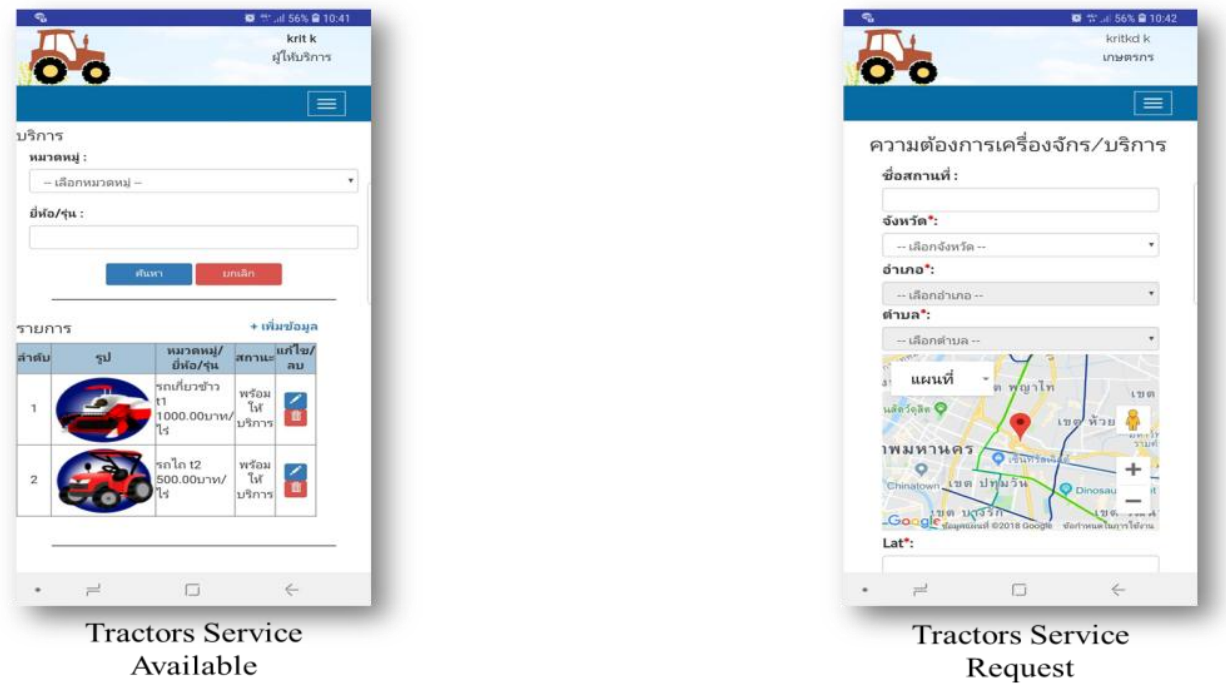

\section{Results}

To evaluate the usability and benefits of using SAM-SF for farm machine sharing, we have selected a sample of 80 farmers to use SAM-SF to share their machines among them and experiment on the generation of various sharing models. Then they input availability of theirs machines and use SAM-SF as a collaboration tool to share their machine during the period from Jan 2017 to December 2017. After which, they answered the set of questions and a set of Likert-scale assessment. These volunteers will be referred to as respondent in this section.

Evaluation: In the evaluation of SAM-SF, the respondents were $60 \%$ using machine for production, $30 \%$ using machine for harvesting, and $10 \%$ using machine for primary processing \& storage. Our respondents are farmers who experience using mobile phone.

Findings: The respondents are $65 \%$ farmers who own agricultural machine and $35 \%$ are farmers who do not own any agricultural machine. Most of them are young adults between 22 and 40 years old. We also collect the annual income, and information about their planting crops and its season for production, 
harvesting and primary processing \& storage. A total of $20 \%$ of the respondents plant their crops at the beginning of rainy season, in May to July and 30\% plant their crops Planted before the end of rainy season, in December to February and the rest 50\% planted their crops all year round. Harvesting and primary processing \& storage duration are various based on what kind of crops and theirs yield. Overall, the respondents, after using SAM-SF for trip planning and real-time adjustment of the trip plan feel that the SAM$\mathrm{SF}$ is a trusted tool for sourcing farming machinery when needed. Compare SAM-SF to the conventional advice from friends and internet search, the SAM-SF recommends available machine is very acceptable in terms of where it located, how far of the available machine form the farm (distance between farm and the available machine), information about the machine as well as the rental model.

\section{Conclusion}

This model is an experiment for Thais farmer in relationship with smart equipment and internet technology. The result show that more than $90 \%$ of the sampling (Thai farmers) satisfied with this model.

SAM-SF is an essential tool for a farmer to collaborate their machine sharing. A user can specify types and number of machines needed with related information including the specific features, or let the system retrieve available machine nearby shown on the google map. The user can use SAM-SF to offer their idle machine to others by check-in the machine location and brief description about its functions as well as taking the photo of the machine using mobile device. During using the machine, the owner can use SAM-SF to monitor his asset borrow to other. After all processes, the user can manage his assets back to his farm or sending directly to the new matching farm, if any. Since SAM-SF interfaces with google mapping function, it derives all the benefits of identifying current position, time to destination, street view, and alternate route.

From the evaluation data, most of the people who have used the SAM-SF gave very favorable rating. So, to deploy SAM-SF for public use, a cloud-based implementation can be carried out so that it can be accessed from any location. Moreover, the model itself can be generalized and extended to cover over all farming area in in Thailand. As for extending work, the development a farming network base on the concept of SAM-SF Platform, which not only the farmers can register to share various agricultural tools, but also manufacturers of machine tool vendors and other agricultural products can be registered for purchase, offering, and maintenance services through the SAM-SF Platform. This future work must also take into consideration of create trust model using blockchain and smart contract to ensure all real matching deal including payment method to receive and pay rental fee or service charge. In summary, SAM-SF is a new way for farmers to collaborate in real time to build a peer-to-peer network of sharing agriculture machinery and equipment.

\section{References}

Sousa, A. J., Fedec, A. \& IECONOMICS, INC. (n.d.). Retrieved from Trading Economics: https://tradingeconomics.com/thailand/gdp-from-agriculture

Agricultural value chains. (2018, September 29). Integrated risks and optimal financing in the one district, one factory programme. Retrieved from B\&FT.

Basarik, A. \& Yildirim, S. (2015). A Case study of Sharing Farm Machinery in Turkey,). International Journal of Natural and Engineering Sciences, 9(3).

Bukht, R. \& Heeks, R. (2018). Development Implications of Digital Economies. University of Manchester, Global Development Institute, SEED. Manchester: Centre for Development Informatics. Retrieved November 14, 2018

Chatchalearmpol, A., Pongsuwan, W. \& Vachalobol, L. (2016, June). Social Media Perception Affecting the Business of PTT Public Company Limited. Information Management and Business Review, 8(3), 58-64.

Country Profile Thailand. (n.d.). (Department of Agriculture (DOA)) Retrieved November 15, 2018, from http://www.intracen.org/exporters/organic-products/country-focus/Country-Profile-Thailand/

Doungvichitkul, S., Pongsuwan, W. \& Thanawastien, S. (2016). Social Communication for Smart Farmers: A Case Study on Durian Farmers. The Asian Symposium on Education, Equity and Social Justice, (pp. Equity and Social Justice, August 2-3, 2016. Fukuoka, Japan ISSN 2188-6865.).

Fukuoka. (2017, January 5). What is Thailand 4.0 - ไทยแลนด์ 4.0 คืออะไร. IT 24 hrs. Retrieved March 14, 2018, from https://www.it24hrs.com/2017/thailand-4-0/ 
it24hrs. (2018, April 5). NBTC discloses statistics on the use of mobile phones in Thailand in 2018 using the mobile network hit 3 million terabytes. IT 24 hrs. Retrieved from www.it24hrs.com: https://www.it24hrs.com/2018/smartphone-thailand-3g-4g-static-data/

Khongmanee, P., Pongsuwan, W. \& Thanawastien, S. (2017). Smart Drivers: Travelling Management for Smart Employees. Elixir International Journal Behaviour, 112.

NBTC, The Office of National Broadcasting and Telecommunications Commission. (2018). Mobile Subscribers in Thailand. Division of Telecommunication Economics Research and Information Center, Telecommunication Policy and Resource Management Bureau.

OECD. (2013). Structural Policy Country Notes for Emerging Asia. Economic Outlook for Southeast Asia. Paris: OECD Publishing.

Thailand Rural population percent. (n.d.). (The World Bank), Retrieved October 20, 2018, from The Global Economy.

Business Process Model and Notation. (n.d.). In Wikipedia. 